\title{
Oligodendroglial tumours: subventricular zone involvement and seizure history are associated with $\mathrm{ClC}$ mutation status
}

\author{
Zhenyin Liu ${ }^{\dagger}$, Hongsheng Liu ${ }^{\dagger}$, Zhenqing Liu and Jing Zhang ${ }^{*}$ (D)
}

\begin{abstract}
Background: CIC-mutant oligodendroglial tumours linked to better prognosis. We aim to investigate associations between $\mathrm{CIC}$ gene mutation status, MR characteristics and clinical features.

Methods: Imaging and genomic data from the Cancer Genome Atlas and the Cancer Imaging Archive (TCGA/TCIA) for 59 patients with oligodendroglial tumours were used. Differences between $\mathrm{CIC}$ mutation and CIC wild-type were tested using Chi-square test and binary logistic regression analysis.

Results: In univariate analysis, the clinical variables and MR features, which consisted 3 selected features (subventricular zone[SVZ] involvement, volume and seizure history) were associated with CIC mutation status (all $p<0.05$ ). A multivariate logistic regression analysis identified that seizure history (no vs. yes odd ratio [OR]: 28.960, 95 confidence interval [CI]:2.625-319.49, $p=0.006$ ) and SVZ involvement (SVZ- vs. SVZ+ OR: 77.092, $p=0.003$; 95\% Cl: 4.578-1298.334) were associated with a higher incidence of CIC mutation status. The nomogram showed good discrimination, with a C-index of 0.906 (95\% Cl: 0.812-1.000) and was well calibrated. SVZ- group has increased (SVZ- vs. SVZ+, hazard ratio [HR]: 4.500, $p=0.04 ; 95 \%$ Cl: 1.069-18.945) overall survival.

Conclusions: Absence of seizure history and SVZ involvement (-) was associated with a higher incidence of $\mathrm{ClC}$ mutation.

Keywords: Oligodendroglial Tumours, CIC mutation, Subventricular zone involvement, Logistic regression, Seizure history
\end{abstract}

\section{Background}

Low-grade gliomas (LGGs) exhibiting oligodendroglial features include oligodendrogliomas and oligoastrocytomas [1]. The updated 2016 edition of the World Health Organization (WHO) Classification of tumors of the Central Nervous System (CNS) uses molecular parameters and the histology to define the main tumor categories for the first time. This represents a shift from the traditional principle of using neuropathological diagnoses, which are primarily based on the microscopic features, to using molecularly-oriented diagnoses $[2,3]$. Therefore, neurosurgeons increasingly depend on molecular genetic features to guide their clinical judgement and

\footnotetext{
* Correspondence: dorzhangjing@126.com

†Zhenyin Liu and Hongsheng Liu contributed equally to this work. Department of medical imaging, Guangzhou women and children's medical center, Guangzhou medical university, Jinsui road 9 \#, Guangzhou City 510623, People's Republic of China
}

decision-making processes [4, 5]. LGG samples with an isocitrate dehydrogenase (IDH) mutation and the codeletion of $1 \mathrm{p}$ and $19 \mathrm{q}$ had the most favourable outcomes for treatment $[6,7]$.

The Capicua transcriptional repressor (CIC) gene is often mutated in oligodendroglial tumours with the codeletion of $1 \mathrm{p}$ and $19 \mathrm{q}$. CIC-mutant oligodendroglial tumours are also associated with better prognoses $[8,9]$ and to better treatment outcomes and overall survival [8-10]. In the field of MR radiogenomics research, many imaging-based characteristics (tumour localization, mass effect, tumour contrast enhancement, etc.) are correlated with molecular genetic biomarkers (EGFR, IDH/1p19q subtype, TP53 mutation status, etc.) that are used to identify their phenotypes upon imaging [8, 11-15]. Recent studies have also found that the heterogeneity in patient 
prognoses might be linked to neuronal stem cells (NSCs), located in the subventricular zone (SVZ) [8, 16, 17].

To date, although several studies have evaluated MRI characteristics as they relate to IDH/1p19q status [18, 19], no study has investigated associations between CIC mutation status and MR imaging features in oligodendroglial tumours. Radiological detection of CIC mutation status may facilitate the preoperative prediction of a patient's prognosis. Therefore, this paper reports preliminary research that can be used to determine the associations between CIC gene mutation status, MR characteristics and clinical features.

\section{Methods}

\section{Patient population}

All patient data was acquired from the published The Cancer Genome Atlas LowGrade Glioma (TCGA-LGG) project and within this publication it is stated "Specimens were obtained from patients, with appropriate consent from institutional review boards". (http:// cancergenome.nih.gov/).

The clinical files of oligodendroglial tumours were downloaded from the TCGA data portal (https://tcgadata.nci.nih.gov/tcga/dataAccessMatrix.htm;updated: 2018-08-23). MR datawere provided by TCIA (updated: 2014-09-04).TCGA and TCIA are publicly available databases that contain no linkage to patient identifiers. All patients must meet the following criteria to enter our study: available pathologic diagnosis of oligodendroglial tumours (oligodendroglioma or oligoastrocytoma) from TCGA; available CIC mutation status (CIC mutation or CIC wild-type) from TCGA [20] (extracted from a previous study [N
Engl J Med. 2015; 372 (26):2481-2498]); and available MR images (T1WI, T2WI, Flair and post-contrast) from TCIA. Finally, 59 patients with oligodendroglial tumours were used in this institutional review board approval-exempt study.

\section{Image feature analysis}

The MR images were presented to two radiologists for interpretation and measurement and in cases of disagreement a consensus was reached after discussion. Both radiologists were blind to $\mathrm{CIC}$ mutation status and clinical information. The following 7 qualitative MR imaging features [11, 12, 21, 22] were evaluated: (1) volume $\left(<60 \mathrm{~cm}^{3}\right.$ vs. $\left.\geq 60 \mathrm{~cm}^{3}\right)$; (2) multifocal (no vs. yes); (3) intratumoural haemorrhaging (no vs. yes); (4) enhancing margin (well defined vs. poorly defined); (5) necrosis (no vs. yes); (6) proportion of contrastenhanced tumour $(<5 \%$ vs. $\geq 5 \%)$; and (7) SVZ Involvement (no vs. yes). The tumours that were located in close contact with the SVZ were classified as SVZ+, while the tumours that were located distantly from the SVZ were classified as SVZ- ${ }^{17}$.

\section{Statistical analysis}

Differences between CIC mutation and CIC wild-type were tested using the Chi-square test and binary logistic regression analysis (version 22.0; SPSS Company, Chicago, IL). Odd ratios (OR) and 95\% confidence intervals $(\mathrm{CI})$ are reported. The area under the receiver operator characteristic curve (AUC) was estimated for prediction of CIC gene mutation status. The sensitivity, specificity, positive likelihood ratio (PLR) and negative likelihood ratio (NLR) of the model in the prediction of CIC mutations were

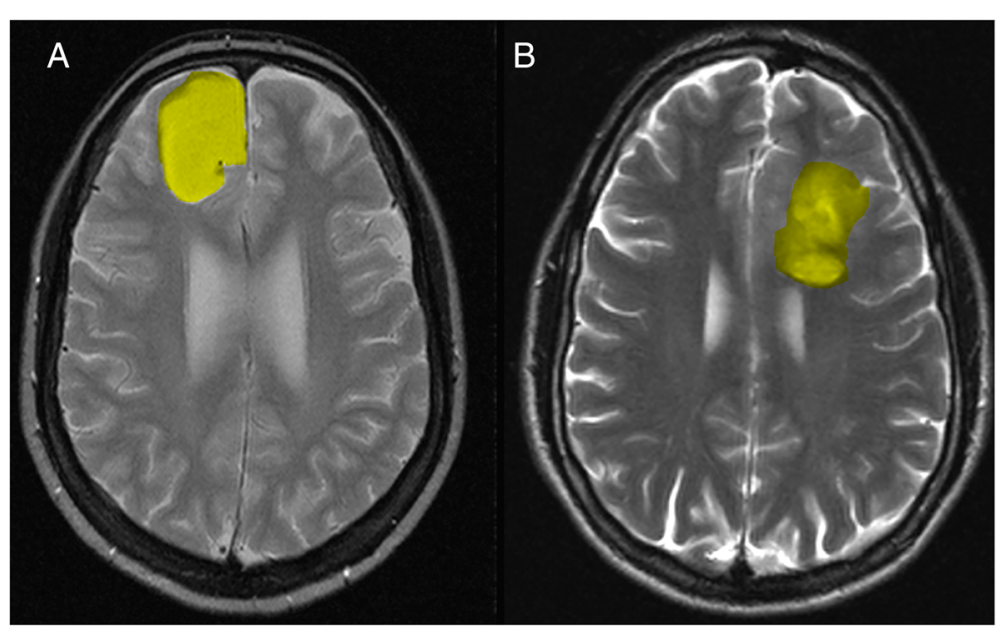

Fig. 1 Tumor (T2-weighted MR images) localization in the cortex without subventricular zone involvement (a). Tumor (T2-weighted MR images) with infiltration of the subventricular zone (b) 
Table 1 Association between clinical and MR features and CIC mutation status (follow up: 0.03-156.11 months)

\begin{tabular}{|c|c|c|c|c|}
\hline & $\begin{array}{l}\text { No. of CIC } \\
\text { Wild-Type }\end{array}$ & $\begin{array}{l}\text { No. of } \mathrm{CIC} \\
\text { Mutations }\end{array}$ & $x^{2}$ & $P$ \\
\hline Age & & & 0.08 & 0.777 \\
\hline$<40$ year & 20 & 3 & & \\
\hline$>=40$ years & 29 & 7 & & \\
\hline Sex & & & 0.083 & 0.773 \\
\hline Female & 24 & 6 & & \\
\hline Male & 25 & 4 & & \\
\hline Race Category & & & 0.179 & 0.672 \\
\hline $\begin{array}{l}\text { Black or African } \\
\text { American }\end{array}$ & 3 & 1 & & \\
\hline White & 46 & 9 & & \\
\hline Seizure History & & & 7.538 & $0.023^{*}$ \\
\hline No & 12 & 7 & & \\
\hline Yes & 36 & 3 & & \\
\hline KPS & & & 3.334 & 0.068 \\
\hline$<80$ & 4 & 2 & & \\
\hline$>=80$ & 27 & 2 & & \\
\hline Primary Tumor Laterality & & & 0.183 & 0.669 \\
\hline Left & 18 & 5 & & \\
\hline Right & 31 & 5 & & \\
\hline Volume & & & 7.687 & $0.006^{*}$ \\
\hline$<60 \mathrm{~cm}^{3}$ & 10 & 7 & & \\
\hline$>=60 \mathrm{~cm}^{3}$ & 39 & 3 & & \\
\hline Multifocal & & & 0.234 & 0.651 \\
\hline No & 48 & 10 & & \\
\hline Yes & 1 & 0 & & \\
\hline $\begin{array}{l}\text { Intratumoral } \\
\text { hemorrhage }\end{array}$ & & & 0.308 & 0.579 \\
\hline No & 45 & 8 & & \\
\hline Yes & 4 & 2 & & \\
\hline Enhancing margin & & & 1.632 & 0.201 \\
\hline Well Defined & 18 & 1 & & \\
\hline Poorly Defined & 31 & 9 & & \\
\hline Necrosis & & & $<0.001$ & 1 \\
\hline No & 6 & 1 & & \\
\hline Yes & 43 & 9 & & \\
\hline $\begin{array}{l}\text { Proportion contrast- } \\
\text { enhanced tumor }\end{array}$ & & & 2.649 & 0.104 \\
\hline$<5 \%$ & 34 & 10 & & \\
\hline$>=5 \%$ & 15 & 0 & & \\
\hline $\begin{array}{l}\text { Subventricular Zone } \\
\text { Involvement }\end{array}$ & & & 9.802 & $0.002^{*}$ \\
\hline No & 15 & 9 & & \\
\hline Yes & 34 & 1 & & \\
\hline
\end{tabular}

obtained. Survival analysis (SVZ- vs. SVZ+) was estimated using the Cox proportional hazards models. Hazard ratios (HR) and 95\% CI are reported. The statistical significance threshold was set at a $P$-value of 0.05 (two-sided) to indicate statistical significance.

\section{Results}

Our series of 59 patients ( $45.4 \pm 14.0$ years, range: $18-74$ years) included 29 men (49.2\%) and 30 (50.8\%) women. CIC mutations were found in $10(16.9 \%)$ of 59 patients. There were 35 patients $(59.3 \%)$ with tumours that involved the SVZ (Fig. 1). Specifically, 8 tumours involved the frontal horn, 5 the body, 1 the occipital horn, 17 the temporal horn and 4 others. The cohort mean OS was 37.5 months (range: $0.03-156.11$ and median $=21.4$ ), and 44 patients were still alive $(74.6 \%)$ at the end of the study while 15 were deceased (25.4\%). Clinical data are summarized in Table 1 and Additional file 1: Table S1.

In univariate analysis, the clinical variables and MR features, which consisted of three selected features (SVZ involvement, volume and seizure history) were significantly associated with CIC mutation status (all $P<0.05$ ). We demonstrated that a smaller tumour volume (OR: 9.100, $P=0.004)$, SVZ-(OR: $20.400 P=0.006)$ and a history absent of seizures (OR: 6.462, $P=0.014$ ) were associated with a significantly higher incidence of CIC mutations (Table 1 Fig. 2).

In multivariate logistic regression analysis, only two risk factors were significant independent predictors (Table 2). We demonstrated that seizure history (no vs. yes OR: 28.960, 95CI:2.625-319.49, $P=0.006$ ) and subventricular zone involvement (SVZ- vs. SVZ+ OR: 77.092, $P=0.003$; 95\% CI: 4.578-1298.334) were associated with a higher incidence of CIC mutation status. The nomogram displayed high discrimination, with a Cindex of 0.906 (95\% CI: $0.812-1.000)$ and was well

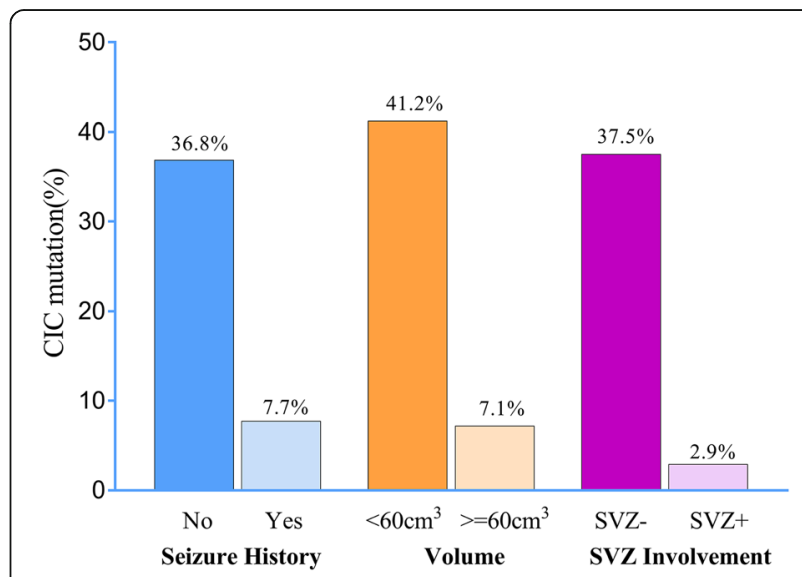

Fig. 2 Smaller tumor volume, SVZ- and absent seizure history were associated with a significantly higher incidence of $\mathrm{CIC}$ mutation (univariate analysis $P<0.05$ ) 
Table 2 binary logistic regression analysis of prognostic factors for $\mathrm{CIC}$ mutation status

\begin{tabular}{|c|c|c|c|c|c|}
\hline & \multirow[t]{2}{*}{ Wald } & \multirow[t]{2}{*}{ Sig. } & \multirow[t]{2}{*}{ OR } & \multicolumn{2}{|c|}{$95.0 \% \mathrm{Cl}$ for OR } \\
\hline & & & & Lower & Upper \\
\hline Subventricular Zone Involvement & 9.095 & $0.003^{*}$ & 77.092 & 4.578 & 1298.334 \\
\hline Seizure History & 7.551 & $0.006^{*}$ & 28.960 & 2.625 & 319.49 \\
\hline Constant & 14.378 & $0.000^{*}$ & 0.003 & & \\
\hline
\end{tabular}

${ }^{*} P<0.05$

calibrated (Fig. 3). The sensitivity, specificity, positive likelihood ratio (PLR) and negative likelihood ratio (NLR) of this model in the prediction of CIC mutations were $0.90,0.71,3.09$ and 0.14, respectively. Subventricular zone involvement (-) of oligodendroglial tumours in combination with absence of seizure history may therefore be used to better prognosticate CIC mutation status than the use of each variable alone (Fig. 4).

Patients (follow up: 0.03-156.11 months) with SVZhad a longer median overall survival (133.6 vs.65.7)

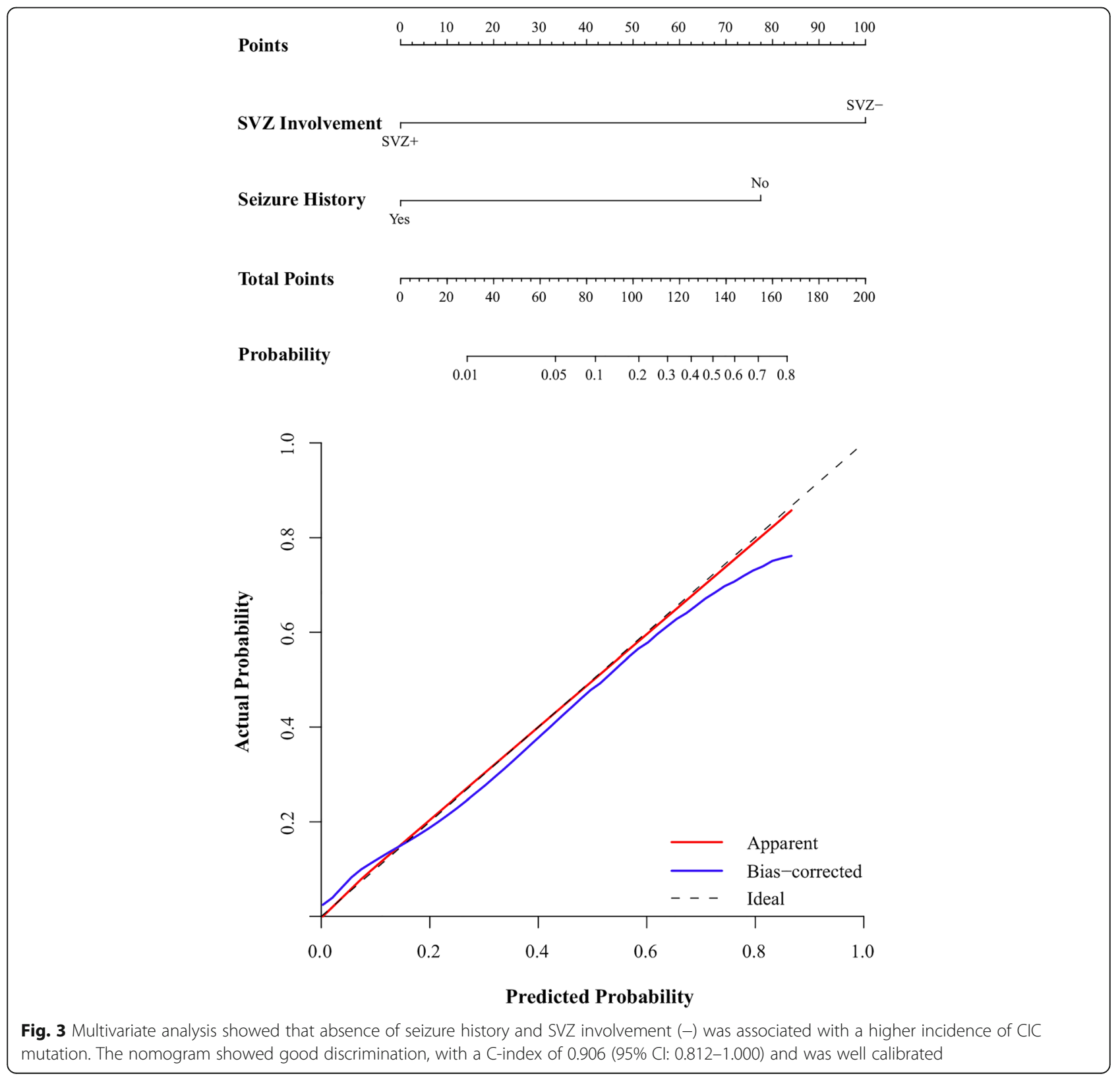




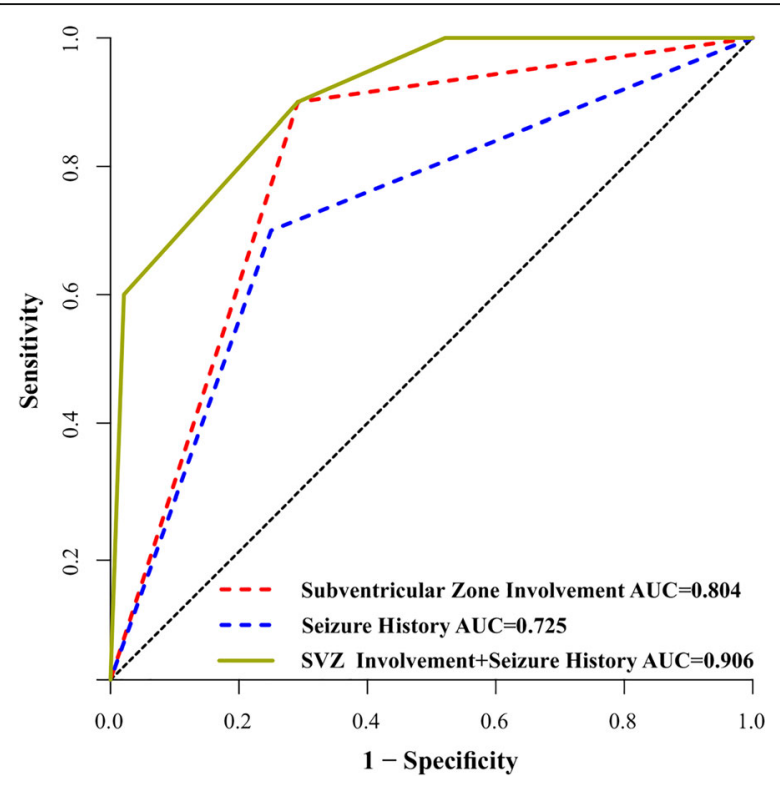

Fig. 4 ROC curve analysis showed that subventricular zone involvement of oligodendroglial tumors in combination with seizure history may therefore be used to prognosticate CIC mutation status better than use of variables alone

months (SVZ- vs. SVZ+, hazard ratio (HR): 4.500, $P=0.04 ; 95 \%$ CI: $1.069-18.945)$ than patients with SVZ+(Fig. 5). SVZ+ tumors were significantly larger than SVZ- tumors $\left(181 \pm 92.1 \mathrm{~cm}^{3}\right.$ vs. $117 \pm 116 \mathrm{~cm}^{3}$, $P<0.05)$.

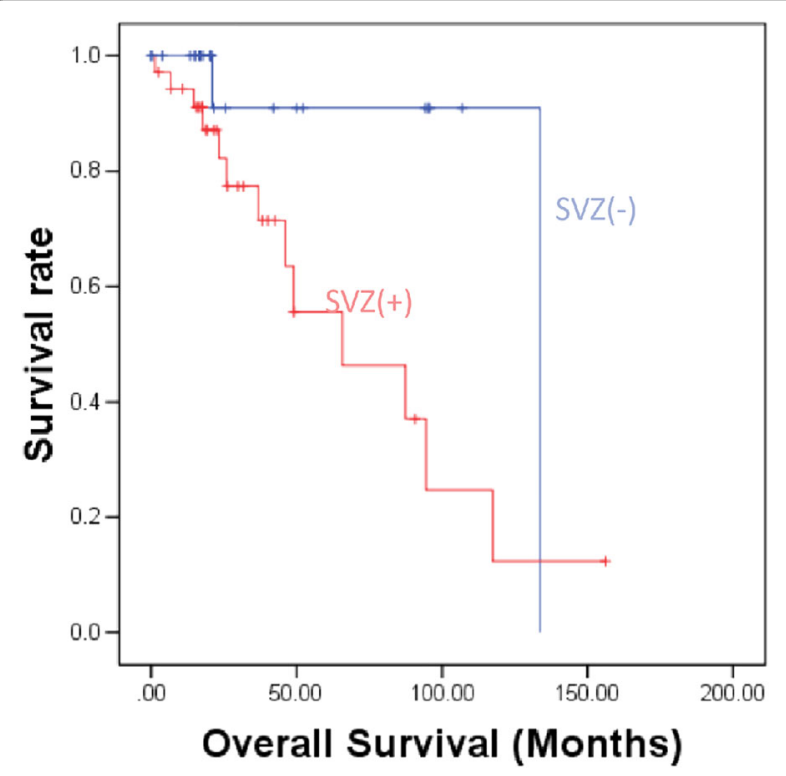

Fig. 5 Overall survival outcomes of patients with tumors contacting the SVZ, and those with tumors not involved in the SVZ (log rank $=5.029, P=0.025)$

\section{Discussion}

Molecular genetic studies demonstrated distinct glioma entities with specific epigenetic and genetic profiles [23]. Some oligoastrocytomas and most oligodendrogliomas are characterized by a typical and unique unbalanced translocation, der $(1,19)$, resulting in a $1 \mathrm{p} / 19 \mathrm{q}$ codeletion (codeletion of $1 \mathrm{p}$ and $19 \mathrm{q}$ ). Candidate tumour suppressor genes (TSGs) targeted by these losses, including FUBP1 on 1p31.1 and CIC on 19q13.2, were only recently discovered [10]. CIC-mutant oligodendroglial tumours are also linked to better prognoses $[8,9]$.

There are a number of studies regarding the relationship between imaging features and gene mutations. Rios Velazquez E et al. [24] confirmed that quantitative features related to intratumour heterogeneity that were able to successfully discriminate $(\mathrm{AUC}=0.69)$ between EGFR- and EGFR+ lesions. Brendle $\mathrm{C}$ et al. [25] showed that the differentiation of high-grade gliomas and lowgrade gliomas (sensitivity: $100 \%$ specificity: $80 \%$ ) is made possible by the dynamic contrast-enhanced MR perfusion parameter Ve $(P=0.024)$, while arterial spin labelling perfusion shows the potential for the discrimination of the ATRX and IDH mutation statuses (sensitivity: 75\% specificity: $88 \%, P=0.014$ ). Dagher J [26] implied that wild-type von Hippel-Lindau (VHL) renal cell carcinomas were associated with lymph nodal metastases. Rizzo S [27] found that a pleural effusion related to ALK mutations while nodules located in non-tumour lobes or round lesion shapes were related to a KRAS mutation in subgroups of non-small cell lung cancer patients. So far, no study has investigated associations between $\mathrm{CIC} \mathrm{mu-}$ tation status and MR imaging features in oligodendroglial tumours. This study suggests that SVZ involvement and seizure history can be conveniently used to facilitate the prediction of $\mathrm{CIC}$ mutation status.

The subventricular zone has been associated with the origination and development, as well as the biological behaviour of LGGs [22]. Recently, limited studies have reported associations between SVZ involvement and patient prognosis. Nakagawa $\mathrm{Y}$ et al. [28] implied that the loss of $19 \mathrm{q}$ and lack of SVZ+ might be prognostic for longer survival. Liu $S$ et al. [22] reported that multivariate analysis showed that a shorter distance between the tumor centroid and the SVZ $(p=0.039)$ was significantly associated with poor overall survival in SVZinvolved patients (low-grade astrocytoma). Liu S et al. [22] also reported that a longer distance between the SVZ and the tumour centroid was significantly related to better overall survival in SVZ-involved LGG patients. Adeberg $\mathrm{S}$ et al. [8] confirmed that the tumour location with regard to the subventricular zone is related to a patient's prognosis $(p<0.05)$.

Nomograms are user-friendly tools that give relative contexts and probabilities of cancer prognoses [11]. In 
the present study, we constructed three models for the preoperative prediction of $\mathrm{CIC}$ mutation statuses in oligodendroglial tumours. ROC curve analysis showed that use of seizure history combined with SVZ involvement $(\mathrm{AUC}=0.906)$ was superior to simply the use of seizure history (AUC $=0.725$ ) or SVZ involvement alone $($ AUC $=0.804)$. The discriminatory power of the nomogram which combined SVZ involvement and seizure history was also very strong and well calibrated.

The limitations of our study included the retrospective nature of our data collection, the relatively limited number of cases $(n=59)$ and the automatic imaging feature extraction not being implemented. In addition, we do not know whether re-classification by an expert neuropathologist has been performed, however, similar to other papers (2017-2019 more than 250 articles) published using this dataset, we therefore believe our conclusions are not largely influence by such factors. Further study should be conducted by using a larger pool of oligodendroglial tumours patients with the use quantitative image analysis tools being required [29]. The newly emerged field of radiogenomics allows specific MR imaging phenotypes to be linked with gene expression profiles. Further work is needed to better define the relationships identified in our study and to explore additional relationships (SVZ involvement and CD133, SVZ involvement and CD44, SVZ involvement and MMPs).

\section{Conclusions}

In conclusion, this study presents that SVZ involvement $(-)$ and absence of seizure history may therefore be used to facilitate the prediction of CIC mutation status. Patients with SVZ- had a longer median overall survival months than patients with SVZ+.This work represents a practical application of imaging findings for personalized medicine. External validation of this model in other cohorts of patients is needed.

\section{Additional file}

Additional file 1: Table S1. Clinical data of this study. (XLS $71 \mathrm{~kb}$ )

\section{Abbreviations}

AUC: Area under the curve; $\mathrm{Cl}$ : Confidence interval; CIC: Capicua transcriptional repressor; HR: Hazard ratio; IDH: Isocitrate dehydrogenase; LGG: Low-grade gliomas; NLR: Negative likelihood ratio; NSCs: Neuronal stem cells; OR: Odds ratio; PLR: Positive likelihood ratio; SVZ: Subventricular zone; TCIA: The Cancer Imaging Archive; TSGs: Tumor suppressor genes

\section{Acknowledgements}

None.

\section{Authors' contributions}

ZYL and HSL performed the statistical analysis and drafted the manuscript, $J Z, Z Q L, H S L$ and ZYL participated in the design of the study and helped to draft the manuscript, JZ and ZYL collected the data, JZ and ZYL helped to perform the statistical analysis, JZ conceived of the study and participated in the design of the study. All authors read the approved the final manuscript.

\section{Funding}

Supported by a grant from the Medical and Health Science and Technology Project of Guangzhou (No. 20161A011022) and partially supported by the fund from Guangzhou Institute of Pediatrics/Guangzhou Women and Children's Medical Center/(NO:IP-2016-002). The funding body did not play any role in design, in the collection, analysis, and interpretation of data; in the writing of the manuscript; and in the decision to submit the manuscript for publication.

\section{Availability of data and materials}

All data generated or analyzed in this study are included in this published article and its Additional files.

\section{Ethics approval and consent to participate}

All patient data was acquired from the published The Cancer Genome Atlas Low Grade Glioma (TCGA-LGG) project and within this publication it is stated "Specimens were obtained from patients, with appropriate consent from institutional review boards". (http://cancergenome.nih.gov/).

\section{Consent for publication}

Not applicable.

\section{Competing interests}

The authors declare that they have no competing interests.

Received: 15 September 2018 Accepted: 6 June 2019

Published online: 18 June 2019

\section{References}

1. Michaud K, de Tayrac M, D'Astous M, Duval C, Paquet C, Samassekou O, et al. Contribution of $1 \mathrm{p}, 19 q, 9 p$ and $10 q$ automated analysis by FISH to the diagnosis and prognosis of Oligodendroglial tumors according to WHO 2016 guidelines. PLoS One. 2016:11(12):e0168728.

2. Komori T. The 2016 WHO classification of Tumours of the central nervous system: the major points of revision. Neurol Med Chir (Tokyo). 2017:57(7):301-11.

3. Carter JH, McNulty SN, Cimino PJ, Cottrell CE, Heusel JW, Vigh-Conrad KA, et al. Targeted next-generation sequencing in molecular subtyping of lowergrade diffuse gliomas: application of the World Health Organization's 2016 revised criteria for central nervous system tumors. J Mol Diagn. 2017;19(2):328-37

4. Sturm D, Pfister SM, Jones DTW. Pediatric gliomas: current concepts on diagnosis, biology, and clinical management. J Clin Oncol. 2017;35(21):2370-7.

5. Michotte A, Neyns B, Chaskis C, Sadones J. Neuropathological and molecular aspects of low-grade and high-grade gliomas. Acta Neurol Belg. 2004;104(4):148-53.

6. Liu Z, Zhang T, Jiang H, Xu W, Zhang J. Conventional MR-based preoperative nomograms for prediction of IDH/1p19q subtype in low-grade glioma. Acad Radiol. 2018.

7. Wu CC, Jain R, Radmanesh A, Poisson LM, Guo WY, Zagzag D, et al. Predicting genotype and survival in glioma using standard clinical MR imaging apparent diffusion coefficient images: a pilot study from the Cancer genome atlas. AJNR Am J Neuroradiol. 2018;39(10):1814-20.

8. Adeberg S, Bostel T, Konig L, Welzel T, Debus J, Combs SE. A comparison of long-term survivors and short-term survivors with glioblastoma, subventricular zone involvement: a predictive factor for survival? Radiat Oncol. 2014:9:95.

9. Gleize V, Alentorn A, Connen de Kerillis L, Labussiere M, Nadaradjane AA, Mundwiller $\mathrm{E}$, et al. CIC inactivating mutations identify aggressive subset of 1p19q codeleted gliomas. Ann Neurol. Sep 2015;78(3):355-74.

10. Eisenreich S, Abou-El-Ardat K, Szafranski K, Campos Valenzuela JA, Rump A, Nigro JM, et al. Novel CIC point mutations and an exon-spanning, homozygous deletion identified in oligodendroglial tumors by a comprehensive genomic approach including transcriptome sequencing. PLoS One. 2013;8(9):e76623.

11. Wang Y, Liu S, Fan X, Li S, Wang R, Wang L, et al. Age-associated brain regions in gliomas: a volumetric analysis. J Neuro-Oncol. 2015;123(2):299-306. 
12. Pope WB, Chen JH, Dong J, Carlson MR, Perlina A, Cloughesy TF, et al. Relationship between gene expression and enhancement in glioblastoma multiforme: exploratory DNA microarray analysis. Radiology. 2008;249(1):268-77.

13. Carlson MR, Pope WB, Horvath S, Braunstein JG, Nghiemphu P, Tso CL, et al. Relationship between survival and edema in malignant gliomas: role of vascular endothelial growth factor and neuronal pentraxin 2. Clin Cancer Res May. 2007;13(9):2592-8.

14. Jamshidi N, Diehn M, Bredel M, Kuo MD. Illuminating radiogenomic characteristics of glioblastoma multiforme through integration of MR imaging, messenger RNA expression, and DNA copy number variation. Radiology. 2014;270(1):1-2.

15. Diehn M, Nardini C, Wang DS, McGovern S, Jayaraman M, Liang Y, et al. Identification of noninvasive imaging surrogates for brain tumor geneexpression modules. Proc Natl Acad Sci U S A Apr. 2008:105(13):5213-8.

16. Liu S, Wang Y, Fan X, Ma J, Qiu X, Jiang T. Association of MRl-classified subventricular regions with survival outcomes in patients with anaplastic glioma. Clin Radiol. 2017;72(5):426 e421-6.

17. Gollapalli K, Ghantasala S, Kumar S, Srivastava R, Rapole S, Moiyadi A, et al. Subventricular zone involvement in Glioblastoma - A proteomic evaluation and clinicoradiological correlation. Sci Rep. 2017;7(1):1449

18. Jaffe CC. Imaging and genomics: is there a synergy? Radiology. 2012;264(2):329-31.

19. Rutman AM, Kuo MD. Radiogenomics: creating a link between molecular diagnostics and diagnostic imaging. Eur J Radiol. 2009;70(2):232-41.

20. Cancer Genome Atlas Research N, Brat DJ, Verhaak RG, Aldape KD, Yung WK, Salama SR, et al. Comprehensive, integrative genomic analysis of diffuse lower-grade gliomas. N Engl J Med 2015;372(26):2481-2498.

21. Gutman DA, Dunn WD Jr, Grossmann P, Cooper LA, Holder CA, Ligon KL, et al. Somatic mutations associated with MRI-derived volumetric features in glioblastoma. Neuroradiology. 2015;57(12):1227-37.

22. Liu S, Wang Y, Fan X, Ma J, Ma W, Wang R, et al. Anatomical involvement of the subventricular zone predicts poor survival outcome in low-grade Astrocytomas. PLoS One. 2016;11(4):e0154539.

23. Malzkorn B, Reifenberger G. Practical implications of integrated glioma classification according to the World Health Organization classification of tumors of the central nervous system 2016. Curr Opin Oncol. 2016;28(6):494-501.

24. Rios Velazquez E, Parmar C, Liu Y, Coroller TP, Cruz G, Stringfield O, et al. Somatic mutations drive distinct imaging phenotypes in lung Cancer. Cancer Res. 2017;77(14):3922-30.

25. Brendle C, Hempel JM, Schittenhelm J, Skardelly M, Tabatabai G, Bender B, et al. Glioma grading and determination of IDH mutation status and ATRX loss by DCE and ASL perfusion. Clin Neuroradiol. 2017;28(3):421-8.

26. Dagher J, Kammerer-Jacquet SF, Brunot A, Pladys A, Patard JJ, Bensalah K, et al. Wild-type VHL clear cell renal cell carcinomas are a distinct clinical and histologic entity: a 10-year follow-up. Eur Urol Focus. 2016;1 (3):284-90.

27. Rizzo S, Petrella F, Buscarino V, De Maria F, Raimondi S, Barberis M, et al. CT Radiogenomic characterization of EGFR, K-RAS, and ALK mutations in non-small cell lung Cancer. Eur Radiol. 2016;26(1):32-42.

28. Nakagawa Y, Sasaki H, Ohara K, Ezaki T, Toda M, Ohira T, et al. Clinical and molecular prognostic factors for long-term survival of the patients with glioblastomas in a single institutional consecutive cohort. World Neurosurg. 2017:106:165-73.

29. Bai HX, Lee AM, Yang L, Zhang P, Davatzikos C, Maris JM, et al. Imaging genomics in cancer research: limitations and promises. Br J Radiol. 2016:89(1061):20151030.

\section{Publisher's Note}

Springer Nature remains neutral with regard to jurisdictional claims in published maps and institutional affiliations.

Ready to submit your research? Choose BMC and benefit from:

- fast, convenient online submission

- thorough peer review by experienced researchers in your field

- rapid publication on acceptance

- support for research data, including large and complex data types

- gold Open Access which fosters wider collaboration and increased citations

- maximum visibility for your research: over $100 \mathrm{M}$ website views per year

At $\mathrm{BMC}$, research is always in progress.

Learn more biomedcentral.com/submissions 